\title{
GEDUNG SENI PERTUNJUKAN JAKARTA
}

\author{
Eko Muliady ${ }^{1)}$ \\ 1) Program Studi S1 Arsitektur, Fakultas Teknik, Universitas Tarumanagara, ekomuliady@gmail.com
}

\begin{abstract}
Abstrak
Gedung seni pertunjukan, merupakan wadah bagi para seniman untuk berkarya, baik seni musik, seni peran, maupun seni rupa. Pada umumnya, gedung seni pertunjukan bisa berupa kawasan yang merupakan pusat seni pertunjukan. Semakin banyaknya musisi/seniman yang lahir di Indonesia maupun di dunia, mendorong banyaknya kebutuhan akan fasilitas pertunjukan para musisi tersebut. Di abad ke-21, sudah tercatat hampir 50 pusat seni pertunjuan iconic di dunia yang diakui tidak diragukan lagi kualitasnya. Dari ke-limapuluh gedung tersebut, hanya 5 dari Asia, itu pun di China dan Singpura. Sedangkan di Indonesia, baru beberapa pusat seni pertunjukan. Namun, belum ada yang iconic dan memiliki kualitas akustik yang memadai. Dan dari segi jumlah wisatawan seni pertunjukan Jakarta barat menempati jumlah paling sedikit di antara kawasan lainnnya, ironisnya di Jakarta barat terdapat pusat seni pertunjukan yaitu Kawasan Kota Tua, namun di lihat dari berbagai faktor banyak kekurangan yang kurang mendukung untuk berkembangnya seni di kawasan itu. Atas permasalahan tersebut, maka diperlukan perancangan pusat seni pertunjukan dengan program ruang yang lengkap dari segi tata ruang, aksesibel dari segi pencapaiannya, kualitas akustik yang baik dari segi interior dan dari segi eksterior. Perancangan Gedung Seni Pertunjukan Jakarta ini akan di integrasikan denagn ruang public sekitar, serta bagian eksterior mangambil tema kawasan dan konsep kawasan agar dapat selaras dengan lingkugan sekitar.
\end{abstract}

Kata kunci: akustik, gedung seni pertunjukan, kota tua, ruang publik

\begin{abstract}
The performing arts building is a place for artists to work in art, senior music, acting, visual arts. In general, the theater can consist of a building that is a theater. The more musicians born in Indonesia or in the world, the more needs will be provided. In the 21st century, almost 50 art centers have been accepted for iconic shows in the world that question their quality again. Of the fifty buildings, only 5 are from Asia, even in China and Singapore. While in Indonesia, only a few senior centers were displayed. However, nothing is iconic and has adequate acoustic quality. And in terms of the number of senior tourists in West Jakarta the least number of other regions, ironically in West Jakarta based on senior centers displayed by the Old City, but from a number of factors that are less supportive to develop in the region. Based on these considerations, it is necessary to design a senior center with a complete space program in terms of spatial, accessible in terms of its achievements, acoustic quality both in terms of interior and in terms of exterior. The design of the Jakarta Performing Arts Hall will be integrated with the surrounding public space, and the exterior part will take the theme of the area and the concept of the area so that it can harmonize with the surrounding environment.
\end{abstract}

Keywords: accoustic, old city, public space, theater

\section{PENDAHULUAN}

\section{Latar Belakang}

Seni adalah manifestasi keindahan manusia yang diungkapkan melalui penciptaan suatu karya seni. Seni lahir bersama dengan kelahiran manusia. Keduanya erat berhubungan dan tidak bisa dipisahkan. Dimana ada manusia disitu ada kesenian. Seni merupakan bagian dari kehidupan manusia yang perlu mendapatkan tempat seperti bidang kehidupan lainnya.

Timbulnya hasrat dan keinginan manusia untuk menyaksikan pertunjukan seni yang dipergelarkan oleh orang lain, serta keinginan dari para seniman untuk disaksikan hasil karya 
mereka telah dirasakan sebagai kebutuhan naluri dan spiritual bagi masyarakat yang beradab dan berbudaya. Oleh adanya tuntutan tersebut, pembangunan gedung pertunjukkan seni telah dimulai sejak abad keV SM hingga saat ini, dengan berbagai bentuk yang mencerminkan kondisi dan perkembangan seni pertunjukkan dan kebudayaan masyarakat pada masa itu. Pada zaman modern saat ini, dengan tuntutan masyarakat yang semakin beragam dan selaras dengan perkembangan-perkembangan seni, budaya, ilmu pengetahuan dan teknologi, maka diperlukan suatu wadah dan ruang untuk pertunjukkan seni yang dapat memenuhi tuntutan kebutuhan masyarakat tersebut.

Jakarta sebagai Ibukota Negara Indonesia yang memiliki penduduk yang selalu berfikiran maju, masih belum memiliki sarana kreativitas yang memadai bagi penduduknya untuk menyalurkan bakat seni beserta semua aktivitas yang berkaitan dengan masyarakat, seperti menciptakan, mengapresiasi dan mempagelarkan hasil karya seni. Fasilitas yang memadai merupakan salah satu hal yang mendukung dalam perkembangan seni.

Kota Jakarta ini juga memiliki ragam budaya yang dapat menunjang dan mendukung kegiatan seni. Selain itu, juga memiliki sejarah yang merupakan pusat pemerintahan dari jaman penjajahan Belanda yaitu kawasan Batavia yang sekarang kita kenal sebagai kota tua Jakarta. Kota tua Jakrta ini dapat menjadi daya Tarik tersendiri bagi pengunjung dan wisatawan, jika kawasan ini lebih di kembangkan lagi ini dapat meningkatkan jumlah wisatawan di kawasan tersebut, kawasan kota tua juga di lalui oleh sungai besar yang dapat kita kelola dengan baik, sebagai salah satu fasilitas pendukung yang dapat menjadi satukesatuan dari gedung pertunjukan kesenian itu sendiri.

Perkembangan kesenian di Jakarta mulai berkurang karena adanya modernisasi dan kurangnya fasilitas yang dapat mendukung kesenian itu berkembang, namun jika di kelola dengan baik mengunakaan teknologi modern yang kita akulturasikan dapat membuat sesuatu kesenian itu menarik dan lebih bergairah kembali, Jadi untuk terus menjaga dan melestarikan kesenian termasuk dalam mengarahkan, membina para generasi untuk tetap melestarikan warisan budaya yang nyaris terdampar ini, sungguh merupakan satu prestasi besar yang patut dan selalu harus kita hargai. Kita harus giat melestarikan kebudayaan kita agar tidak lenyap ditelan jaman modernisasi.

Gedung Seni Pertunjukan Jakarta merupakan suatu tempat yang dipergunakan sebagai tempat pagelaran pertunjukan kesenian betawi, baik seni tari, musik maupun drama. Terkait dengan itu maka persyaratan ruang harus dipenuhi sesuai dengan fungsinya, agar pesan yang diungkapkan penyaji seni dapat tertangkap dengan baik sehingga tercapai kualitas pertunjukan yang optimal serta kepuasan bagi penikmatnya mengingat penonton yang memasuki sebuah gedung pertunjukan memiliki hak untuk mendapatkan kenyamanan, keamanan, penerangan yang cukup, pemandangan (viewing) yang menyenangkan dan kualitas bunyi yang baik selain kualitas acaranya itu sendiri.

\section{Batasan masalah}

Secara substansial Pembahasan dititikberatkan pada hal-hal yang berkaitan dengan disiplin ilmu arsitektur, dengan melihat potensi yang dimiliki kawasan kota tua Jakarta. Batasan spasial meliputi aspek konstektual tapak dengan memperhatikan potensi kendala dan prospek ke depan gedung seni pertunjukan Jakarta.

\section{Tujuan penelitian}

- Secara Subyektif

Sebagai pemenuhan syarat tugas akhir Jurusan Arsitektur Fakultas Teknik Universitas Tarumanagara yang nantinya digunakan sebagai pegangan dan pedoman dalam perancangan Gedung Kesenian Betawi di kawasan kota tua Jakarta. 
- Secara Obyektif

- Sebagai sumbangan bagi perkembangan ilmu dan pengetahuan khususnya dibidang arsitektur.

- Membantu menyelesaikan masalah karena mulai berkurangnya minat terhadapat kesenian betawi di Jakarta.

- Sebagai tempat edukasi kebudayaan Betawi bagi masyarakat.

- Sebagai suatu wadah yang memfasilitasi komunitas seni yang diharapkan dapat mengalihkan gaya hidup modern saat ini yang cenderung konsumtif ke arah yang lebih positif (berkreasi).

\section{Metode penelitian}

Metode pembahan laporan ini menggunakan metode analisa deskriptif dan komparatif yaitu dengan memberikan gambaran segala permasalahan dan keadaan yang ada, selanjutnya dilakukan analisa, perbandingan, serta dinilai dari sudut pandang yang relevan untuk mendapatkan kriteria desain dan dasar perancangan. Metode pengumpulan data yang dilakukan adalah metode studi kepustakaan dan observasi lapangan dengan teknik pengumpulan data sebagai berikut:

a. Studi pustaka, dilakukan untuk memperoleh data yang didapat dengan cara studi pustaka/studi literature, data dari instansi terkait, dan browsing internet.

b. Observasi lapangan, dilakukan sebagai pengamatan langsung terhadap objek.

\section{HASIL DAN PEMBAHASAN}

\section{Ide awal}

Ide awal perancangan gedung kesenian seni ini adalah bagaimana menciptakan bangunan untuk mewadahi berbagai seni pertunjukan sekaligus berfungsi sebagai ruang publik, sekaligus membantu meningkatkan jumlah wisatawan, dengan tidak mengesampingkan standar-standar secara global/internasional.

Ide awal biasanya berhubungan dengan kata-kata yang diinginkan dari hasil peracangan. Dalam proyek ini, kata-kata tersebut antara lain megah, hijau, modern, betawi, dan ramai. Megah dalam hal ini adalah skala dan besaran bangunan, jika dibandingkan dengan luas tapak dan bangunan di sekitarnya. Hijau berarti semaksimal mungkin bangunan dberi lahan hijau. Bangunan juga harus terlihat modern, teknilogi tinggi, untuk menarik masyarakat golongan menegah ke atas. Kawasan pusat seni pertunjukan dan kawasan kota tua harus terlihat ramai setiap hari. Keunikan yang ingin ditampilkan dari bangunan ini adalah:

- Kawasan seni pertunjukan yang diintegrasikan dengan kawasan public.biasanya pertunjukan diadakan untuk golongan menegah keatas dan haya pada malam hari, tetapi pada proyek ini harus dirancang agar masyarakat golongan menegah ke bawah masih bias menikmati kawasan sepanjang hard an setiap hari.

- Pemakaina green roof dan vertical greenery = isu yang sedang hangat di Negara tropis. Menurut para ahli, penggunaan atap/dinding rumput dapat mengurangi panas di dalam bangunan dan mengurangi pemanasan global, walaupun di sisi lain masih sulit diaplikasikan di Indonesia karena factor biaya dan pengetahuan struktur.

- Bentuk bangunan yang tidak biasa atau jarang ditemui di Indonesia namun tetap sebanding dengan wilayah/ bentuk bangunan sekitarnya.

- Untuk melengkapi kawasan kota tua yang belum memiliki fasilitas hiburan seni, dan ini akan menjadi satu-satunya gedung kesenian di kawasan kota tua Jakarta.

- Termasuk salah satu kawasan seni pertunjukan yang dapat mewadahi berbagai pertunjukan di Indonesia. Jarang ada kawasan fasilitas seni pertunjukan di Indonesia terutama budaya betawi.

Jika di simpulkan dengan satu kata, maka ide awal konsepnya adalah bangunan ini harus 'berbeda'. 


\section{Konsep Tapak}

Pengelompokan Fungsi

Secara garis besar, Gedung Seni Pertunjukan Jakarta ini dibagi menjadi 2 (dua) kelompok fungsi, yaitu fungsi privat (utama) dan fungsi publik (penunjang). Pengelompokan secara garis besar ini dilakukan berdasarkan fungsi utama kawasan, yaitu untuk pertunjukan (utama) dan untuk public (penunjang).

Dari kedua fungsi tersebut, dipecah lagi menjadi beberapa kelompok berdasarkan pengguna, yaitu para pemain dan manajemen dalam fungsi utama, serta public dan servis dalam fungsi penunjang. Pengelompokkan ini didasari oleh kebutuhanm aksesbilitas, dan provasi masing-masing pengguna. Namun, bukan berarti antara fungsi tidak bias berhubungan, karena pemisahan kedua fungsi besar tersebut hanya implementasi dengan pemisahan bangunan, tetapi tetap dapat berhubungan satu sama lain.

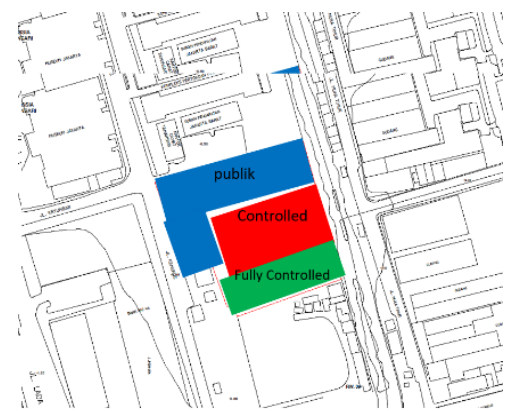

Gambar 1. Penataan Kelompok Fungsi

Sumber: Dokumentasi Pribadi

Pencapaian atau akses menuju tapak dibagi menjadi tiga, yaitu akses oleh akses oleh kendaraam (mobil dan motor), dan akses oleh kendaraan umum (taksi, kereta api, transjakarta, angkutan kota). Kendaraan pribadi pun dibagi menjadi tiga 3 (tiga) kelompok, yaitu kendaraan bagi pegunjung, kendaraan bagi pemain dan manajemen, serta kendaraan servis. Ada pula kendaraan bagi pegunjung yang memiliki akses yang sama dengan pemain/manajemen, yaitu pengunjung khusus (VIP), tetapi terbatas jumlahnya.

Sedangkan bagi pejalan kaki, dengan adanya jalur pendestrian ini di dua titik tersebut, para pengunjung yang tidak menggunakan kendaraan pribadi bias dengan leluasa masuk ke dalam tapak.

Untuk servis seperti logistic, limbah, dan sebagianya, akses disediakan di sebelah timur tapak, karena lebar dan tinggi jalur masuk kendaran lebih leluasa, juga tidak menjadi ha,batan oleh padatnya para pengunjung, pemain, dan manajemen jika sedang ada acara.

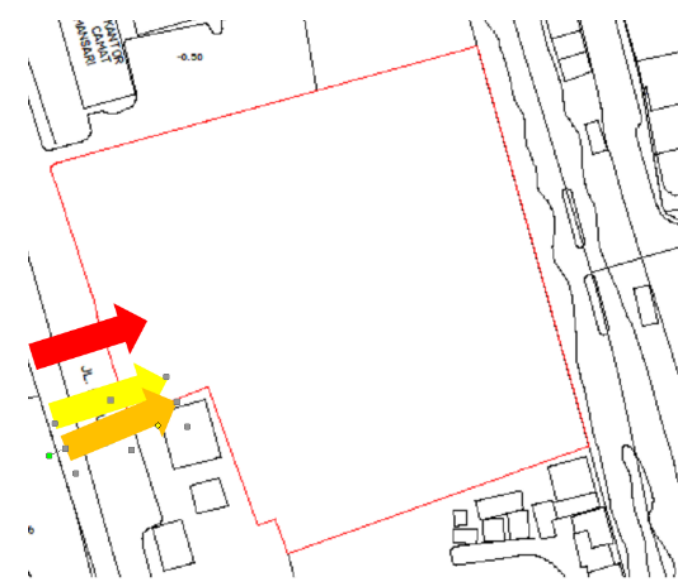

Gambar 2. Arah Pencapaian (Merah: pengunjung, Kuning: pengelola, Orange: servis) Sumber: Dokumentasi Pribadi 


\section{Sirkulasi Luar Bangunan}

Sirkulasi luar bangunan dibagi menjadi 2 (dua) bagian, yaitu entrance dan sirkulasi antar bangunan. Entrance (tempat masuk) ke dalam tapak yaitu entrance utama dan satu satunya di sebelah barat yang akan banyak diakses oleh pejalan kaki karena fasad bangunan lebih banyak menghadap ke barat.

Sirkulasi antar bangunan dalam kawasan gedung pertunjukan ini difasilitasi oleh perkerasan jalur pendestrian yang lebar dan dillindungi oleh canopy dan pohon. Pada sirkulasi diberikan hirarki dengan lebarnya dan bentuk jalur pendestrian. Konsep utama pada sirkulasi pendestrian adalah adanya persilangan alur jalan dalam tapak, sehingga ada titik temu di bagian tapak.

\section{Penataan Massa}

Di dalam kawasan gedung pertunjukan seni ini, terdapat 3 massa bangunan, yaitu bangunan utama yang massif/besar dan tinggi, bangunan penunjang serta teater terbuka semi terbuka karena dirancang menjadi amphitetaer yang beratap tetapi tidak tertutup.

\section{Pembentukan Ruang Luar}

Ruang luar yang terbentuk ada yang disengaja menjadi raung luar seperti atap bangunan penunjuang yang dijadikan ruang luar hijau, ada yang tidak sengaja terbentuk dan dirancang menjadi taman, plaza, kolam, dan jalur pendestrian.

\section{Konsep Bangunan}

Bentuk bangunan, yang dimulai dari denah, merupakan hasil tranformasi dari berbagai ideide dari literature, preseden, dan studi banding dari setiap gedung kesenian. Bentuk bangunan juga dirancang sesuai dengan ciri khas dan budaya kawasan kota tua Jakarta.

Pembentukan bangunan dimulai pada bangunan penunjang, lalu dicerminkan dan disesuaikan dengan kebutuhan ruan gsehingga terbentuk massa bangunant utama. Bangunan penunjang dibuat rata dengan jalan dan diperlakukan sebagai bagian dari landscape. Selain memberikan kesan hirarki bangunan terhadap bangunan utama, bangunan ini pun mempertahankan ruang terbuka hijau dan public, terutama di bagian atap bengunan. Sedangkan bangunan utama lebih diangkat, kontras bentuknya dengan banguna penunjang, untuk menyampaikan pesan bahwa bangunan tersebut merupakan bangunan utama dan memberikan kesan monumental.

\section{Konsep Struktur}

Struktur yang digunakan sederhana. Pada bangunan utama, struktur atap didominasi oleh atap datar, baik dak beton maupun atap dengan kemiringan kecil. Material kolom structural bangunan menggunakan beton, sedangkan dinding menggunakan curtain wall, dengan kolom baja truss.

\section{Konsep Utilitas}

Drainase Tapak

Saluran air yang sebagian besar disimpan di tepi jalur pendestrian, disalurkan melalui selokan yang terletak dibawah jalur pendestrian (eksisting) di tepi tapak, baik disebelah barat, utara, dan selatan tapak. Selokan-selokan tersebut terhubung dengan drainase perkotaan yang besar di sebelah timur yang merupakan kali yang besar.

\section{Penyaluran Air Hujan}

Pada bangunan, penyaluran air hujan dialirkan disalurkan ke jalur-jalur talang yang merupakan bagian dari dak-dak beton. Talang-talang vertikal yang disimpan di sebelah kolom structural ujung bangunan ini diletakkan di sudut-sudit bangunan sehingga tak mengganggu tampak bangunan. Sementara pada area-area yang cenderung terbuka dan tidak memiliki atap 
miring, air hujan akan jatuh ke atas dak beton. Air akan dialirkan ke tepi-tepi plat dimana terdapat saluran air yang akan mengantarkan air hujan ke pipa-pipa vertikal. Dari jalur-jalur air di tanah tersebut, bersama dengan aliran air permukaan tanah kemudian air hujan disalurkan ke saluran air yang terletak di sebelah timur tapak.

\section{Pengkondisian Udara}

Karena bangunan ini merupakan bangunan besar dan terporer pemakainya, walaupun kebutuhan ruang cukup banyak sistem penghawaan udara yang digunakan adalah AC sentral. Pengkondisian udara dalam gedung pertunjukan berfungsi untuk menjaga agar kualitas akustik yang di produksi tidak berkurang serta alat musik yang di gunakan tidak rusak.

\section{Akustik}

Akustik diterapkan pada bangunan auditorium. Amphitheater membutuhkan penanganan akustik yang paling krusial karena volume ruangannya yang besar dan tuntutan akustikalnya yang cukup tinggi. Secara prinsip dinding latar belakang panggung dan sisi belakang penonton harus menggunakan bahan yang menyerap suara yang dalam hal ini digunakan pelapis berupa karpet.

Sementara dinding samping panggung, sepanjang sisi samping auditorium, serta langitlangit harus menggunakan bahan yang dapat memantulkan suara, dalam hal ini adalah material kayu plywood di atas langit-langit, dipadu dengan baja yang berongga pada dinding auditorium, hal ini memperhatikan bahwa kebutuhan untuk melindungi selimut akustik dari gesekan. Selain itu, kemampuan baja memantulkan suara cukup baik. Bidang lantai diberi lapisan luar berupa karpet dan vinyl agar dapat menyerap suara. Dengan begitu suara dari penampil dapat tersebar ke area penonton dengan merata karena adanya dinding-dinding pemantul suara di sisi samping dan langit-langit auditorium.

\section{Elektrikal}

Jaringan elektrikal yang mensuplai kebutuhan energy fasilitas ini berpusat pada sebuah ruang panel yang terletak di basement. Di ruang ini terdapat trafo untuk menerima listrik dari jaringan PLN, genset, serta panel-panel control listrik. Dari transformator ini kemudian dibagi menjadi 2, yaitu untuk massa bangunan, serta satu panel lagi untuk utilitas dan keadaan darurat yang disokong juga oleh genset. Sedangkan untuk menyuplai ke tiap bagian bangunan terdapat raung shaft elektrikal yang terletak di dekat lift.

\section{Pemipaan}

Fasilitas ini memenuhi kebutuhan akan airnya malalui 2 cara, yaitu suplai dari sumur galian serta dari PDAM sebagai sumber cadangan. Untuk suplai dari PDAM, ditangung di sebuah reservoir air bawah tanah. Air dari reservoir ini kemudian dialirkan ke tangki air di atas bangunan dengan menggunakan pompa. Dan kemudian di bagi ke posisisnya masing-masing.

\section{KESIMPULAN DAN SARAN}

\section{Kesimpulan}

Jakarta haruslah menjadi sebuah contoh kota yang akan terus menggunakan kebudayaannya untuk menarik minat para wisatawan. Kebutuhan akan gedung seni pertunjukan mutlak di butuhkan untuk peningkatan wisatawan seni dan budaya di Jakarta. Dengan adanya gedung ini makan banyak masalah yang dapat terselesaikan di luar bidang seni dan budaya.

\section{Saran}

Diharapkan pemerintah juga mendukung terus dan memudahkan pembuatan gedung kesenian dan pelesatarian seni dan budaya Jakarta. 


\section{REFERENSI}

Appleton, Ian. (2008), Buildings for the performing Arts. London: The Architectural Press Ltd. Beranek, Leo L., Music, Acoustics, \& Architecutural, 1962, New York : John wiley \& Sons inc.. Budihardjo, Eko. (1997). Tata Ruang Perkotaan. Bandung: Alimni.

De Chiara, Joseph. (1991).Times Saver Standard for Interior Design and Space Planning. USA : Mcgraw Hill Inc.

Doelle, Leslie L.(1986),Akustik lingkungan, Jakarta : Erlangga.

Ham, Roderick. Theater Planning. 1974, London : The Architectural Press Ltd.

Hardy, Hugh. (1995). Buildings type Basics for Performing Arts Facilities. New Jersey: John Wily \& Sons, Inc.

Specht,Jan. (2014). Architectural Tourism. Springer Gabler.

Neufert, E. (2002).Data Arsitek.Jakarta : Erlangga.

Situs ragam kesenian betawi, http://www.ragamseni.com/tarian-tradisional-dari-betawi-yangwajib-kamu-ketahui/, diakses 03 Juli 2018.

Situs gedung pertunjukan di jakarta, http://www.dewimagazine.com/travel-guide/16-gedungpertunjukan-di-jakarta-wajib-kunjung, diakses 05 Juli 2018.

Situs bacaan effect frank gehry, https://www.theguardian.com/artanddesign/2017/oct/01/bilbao-effect-frank-gehryguggenheim-global-craze, diakses 07 Agustus 2018.

Situs resmi geografis jakarta, https://barat.jakarta.go.id/v12/?p=geografis, diakses 08 Agustus 2018.

Situs resmi tataruang kota jakarta, https://tataruang.jakarta.go.id/publicmap/index.html, diakses 08 Agustus 2018.

Situs data kota Jakarta barat, http://semuadatalengkap.blogspot.com/search/label/Jakarta\%20Barat, diakses 10 Agustus 2018.

Situs persepsi dan partisipasi masyarakat dalam mendukung kota pusaka di kawasan kota tua jakarta, http://repository.ipb.ac.id/handle/123456789/84791, diakses 10 Agustus 2018.

Situs pengembangan kota, https://pengembanganperkotaan.wordpress.com/2011/11/09/teori-teori-perkembangankota/, diakses 11 Agustus 2018. 